\title{
Microvariação na resolução de sujeitos pronominais: português europeu vs. italiano1
}

\author{
Ana Madeira*, Alexandra Fiéis ${ }^{*}$, Joana Teixeira ${ }^{* *}$ \\ *NOVA FCSH e CLUNL \\ ${ }^{* *}$ FLUP \& CLUNL
}

\begin{abstract}
The present study investigates the resolution of null and overt subject pronouns in intrasentential contexts, considering the role of animacy in antecedent assignment. Participants were 15 native speakers of EP and 14 of Italian. Each language group was administered two multiple choice tasks (speeded and untimed), which had a $2 \times 2$ design, crossing the following variables: animacy of the matrix object (animate vs. inanimate) and type of pronominal embedded subject (overt vs. null). Results indicate that there is microvariation in the resolution of overt pronominal subjects in EP and in Italian: the position of the antecedent is the most relevant factor in EP, whereas, in Italian, the animacy of the antecedent is the preponderant factor. Results also show that there is microvariation in the resolution of null subjects (contra previous claims in the literature): the bias for subject antecedents is weaker in Italian than in EP. Possible reasons for the observed microvariation are discussed in detail.
\end{abstract}

Keywords: anaphora resolution, microvariation, animacy, null subject romance languages

Palavras-chave: resolução anafórica, microvariação, animacidade, línguas românicas de sujeito nulo

\section{Introdução}

Tem sido assumido que, nas línguas românicas de sujeito nulo, os sujeitos nulos retomam preferencialmente antecedentes em posição de sujeito, enquanto os sujeitos pronominais plenos tendem a recuperar antecedentes não sujeito (objeto ou referente externo) (e.g., Carminati, 2002; Alonso-Ovalle et al., 2002). No entanto, estudos recentes têm mostrado que existem algumas diferenças entre línguas de sujeito nulo, em particular na resolução de pronomes plenos (e.g., Filiaci, 2010; Filiaci, Sorace \& Carreiras, 2014). As preferências de resolução de sujeitos pronominais plenos parecem variar não só entre línguas, mas também intralinguisticamente consoante a animacidade do antecedente (Cardinaletti \& Starke, 1999; Morgado, Luegi \& Lobo, 2018). Como, em regra, os trabalhos sobre resolução anafórica usam só antecedentes animados, é necessária mais investigação no sentido de compreender o papel da animacidade na resolução das formas pronominais plenas e nulas. Serão também necessários mais estudos comparativos entre línguas de sujeito nulo que incluam o português europeu (PE), que até aqui não tem sido considerado nestes estudos.

No sentido de colmatar estas lacunas, o presente estudo investiga a resolução de sujeitos pronominais nulos e plenos em italiano e PE em contexto intrafrásico, considerando o papel da animacidade do antecedente na posição de objeto. Neste estudo, analisamos contextos pragmaticamente neutros com dois potenciais antecedentes para o sujeito pronominal.

O artigo está organizado da seguinte forma: a secção 2 apresenta uma visão panorâmica dos estudos prévios sobre resolução anafórica em línguas românicas de sujeito nulo; na secção 3, formulamos as questões de

\footnotetext{
${ }^{1}$ Este trabalho foi financiado pela FCT, através do Projeto Estratégico do Centro de Linguística da Universidade Nova de Lisboa UID/LIN/03213/2019. Agradecemos a todos os informantes que participaram no estudo, à Vera Fernandes e Maria Luz pela recolha e tratamento dos dados, e a todos os que, de alguma forma, contribuíram para a realização deste estudo.
} 
investigação e as predições; a secção 4 explica a metodologia do estudo; os seus resultados são descritos na secção 5; e, finalmente, na secção 6, discutimos os resultados e apresentamos as principais conclusões do estudo.

\section{Resolução de sujeitos pronominais em línguas de sujeito nulo}

Nas línguas românicas de sujeito nulo, os sujeitos pronominais nulos e plenos diferem nas suas preferências de interpretação (e.g., Montalbetti, 1984; Costa, Faria \& Matos, 1998; Carminati, 2002; AlonsoOvalle et al., 2002; Luegi, 2012; Lobo, Madeira \& Silva, 2017): enquanto os sujeitos nulos retomam preferencialmente antecedentes em posição de sujeito (1), estando associados à manutenção do tópico discursivo, os sujeitos plenos tendem a recuperar antecedentes noutras posições sintáticas ou referentes extralinguísticos (2), sendo usados para indicar uma mudança de tópico.

(1) A menina $a_{i}$ beijou a avó j $_{\text {quando }}$ pro $_{\mathrm{i}}$ chegou a casa

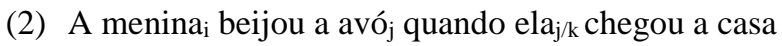

As preferências interpretativas dos sujeitos pronominais podem ser canceladas, por exemplo, por fatores pragmáticos, como se ilustra em (3), em que o sujeito nulo retoma preferencialmente o antecedente extrafrásico:

(3) O João $\mathrm{i}_{\mathrm{i}}$ ño viu o despertador. O Rui $\mathrm{j}_{\mathrm{j}}$ pensa que pro $_{\mathrm{i}}$ vai chegar atrasado.

(Lobo, 2013: 2323)

De acordo com Carminati (2002), estas preferências correspondem a uma estratégia de parsing, designada como a Estratégia da Posição do Antecedente (Position of Antecedent Strategy), segundo a qual "the null pronoun prefers an antecedent which is in the SpecIP position, while the overt pronoun prefers an antecedent which is not in the SpecIP position" (p. 57). Através de uma tarefa de leitura automonitorizada, Carminati (2002) mostra que falantes nativos de italiano adultos processam mais rapidamente frases em que o contexto favorece as leituras preferenciais dos pronomes de sujeito (a leitura de correferência com o sujeito matriz para o sujeito nulo em frases, como em (4a), e a leitura de correferência com o objeto para o sujeito pleno em frases, como em (5b)) do que frases em que o contexto desfavorece estas leituras. Os resultados indicam que existe uma penalização sempre que o contexto força o sujeito pleno a recuperar um antecedente em posição de sujeito (4b) e, em particular, quando o sujeito nulo é forçado a retomar um antecedente em posição de objeto (5a).

(4) Dopo che Giovanni ha messo in imbarazzo Giorgio di fronte a tutti, depois que Giovanni tem posto em embaraço Giorgio de frente a todos a. $\varnothing$ si è scusato ripetutamente $(\varnothing=$ Giovanni $)$ REFLé desculpado repetidamente

b. lui si è scusato ripetutamente (lui = Giovanni) ele REFL é desculpado repetidamente

'Depois de Giovanni ter embaraçado Giorgio. em frente de toda a gente, (ele) pediu desculpa repetidamente'

(Exemplos retirados de Carminatti, 2002:69)

(5) Quando Giovanni ha messo in imbarazzo Giorgio di fronte a tutti, quando Giovanni tem posto em embaraço Giorgio de frente a todos

a. $\varnothing$ si è offeso tremendamente $(\varnothing=$ Giorgio $)$

REFL é ofendido tremendamente 
b. lui si è offeso tremendamente (lui = Giorgio) ele REFL é ofendido tremendamente

'Quando Giovanni embaraçou Giorgio em frente de toda a gente, (ele) ficou muito ofendido'

(Exemplos retirados de Carminatti, 2002:69)

As diferenças de interpretação entre sujeitos nulos e plenos poderão estar relacionadas com as diferentes propriedades gramaticais que caracterizam cada uma das formas (Cardinaletti \& Starke, 1999). O sujeito nulo corresponde a uma categoria gramaticalmente defetiva, o que explica a sua preferência por antecedentes que ocupam uma posição estrutural mais proeminente (i.e., a posição de sujeito). Os sujeitos nulos tendem a ser mais estáveis nas gramáticas nativas adultas e desenvolvem-se mais cedo na aquisição de língua materna (e.g., Lobo, 2016). Já o sujeito pleno é realizado como um pronome forte e a sua resolução é determinada em grande parte por fatores semânticos, pragmáticos e discursivos, envolvendo, assim, custos de processamento mais elevados (e.g., Carminati, 2002; Costa \& Ambulate, 2010).

Alguns estudos recentes sugerem que existe variação entre as línguas de sujeito nulo, em particular no que diz respeito à resolução de sujeitos pronominais plenos. Por exemplo, Filiaci (2010) e Filiaci, Sorace e Carreiras (2014) mostram que, em espanhol, os sujeitos pronominais plenos retomam mais facilmente um antecedente na posição de sujeito do que em italiano. De acordo com estes estudos, no entanto, não se verificam diferenças entre estas duas línguas quanto à interpretação dos sujeitos nulos, que retomam preferencialmente um antecedente em posição de sujeito tanto em espanhol como em italiano. Filiaci, Sorace e Carreiras (2014) avançam a hipótese de que as diferenças observadas na resolução dos sujeitos pronominais entre o italiano e o espanhol poderão estar relacionadas com diferenças na arquitetura dos sistemas pronominais destas duas línguas. Enquanto o italiano apresenta dois tipos de pronomes de sujeito plenos, fortes e fracos, o espanhol dispõe de um único tipo de pronome de sujeito pleno, o que poderá explicar a divisão menos categórica de tarefas entre plenos e nulos nesta língua.

Ao contrário de Filiaci (2010) e Filiaci, Sorace e Carreiras (2014), que testam contextos semelhantes aos ilustrados em (4) e (5) acima, isto é, contextos que favorecem uma interpretação particular para o pronome de sujeito (correferente com o sujeito ou com o objeto da oração matriz), Sorace e Filiaci (2006), no seu estudo sobre resolução anafórica (e catafórica) em italiano L2, testam contextos pragmaticamente neutros como o ilustrado em (6), em que o sujeito pronominal encaixado tanto pode retomar o antecedente em posição de sujeito (la mamma) como o antecedente em posição de objeto (la figlia) ou ainda um referente extralinguístico.

(6) La mamma dà un bacio alla figlia mentre lei/pro si mette il cappotto the mother gives a kiss to.the daughter while she/pro REFL puts the coat 'A mãe beija a filha enquanto (ela) veste o casaco'

(Sorace \& Filiaci, 2006:352)

No que se refere aos sujeitos nulos, os juízos dos falantes nativos de italiano que participaram neste estudo indicam uma tendência de interpretação diferente da observada nos estudos anteriormente referidos, sugerindo que a preferência do sujeito nulo por um antecedente em posição de sujeito em italiano poderá ser atenuada em certas situações. De facto, os resultados apontam para opcionalidade na interpretação do sujeito nulo, que retoma antecedentes tanto em posição de sujeito (51\%) como de objeto (44\%) (cf. Figura 1). Para explicar estes resultados, Sorace e Filiaci (2006) propõem que, neste caso, "the pragmatic plausibility, topicality and accessibility (in terms of recency of presentation) of the complement all converge in overriding the [Position of Antecedent Strategy] and its bias against non-subject referents" (pp. 357-8). Estes resultados contrastam com os verificados para o sujeito pleno (cf. Figura 1), relativamente aos quais os falantes nativos apresentam juízos 
muito mais claros, mostrando uma forte preferência por antecedentes em posição de objeto (82\%), o que está de acordo com o observado em estudos anteriores.

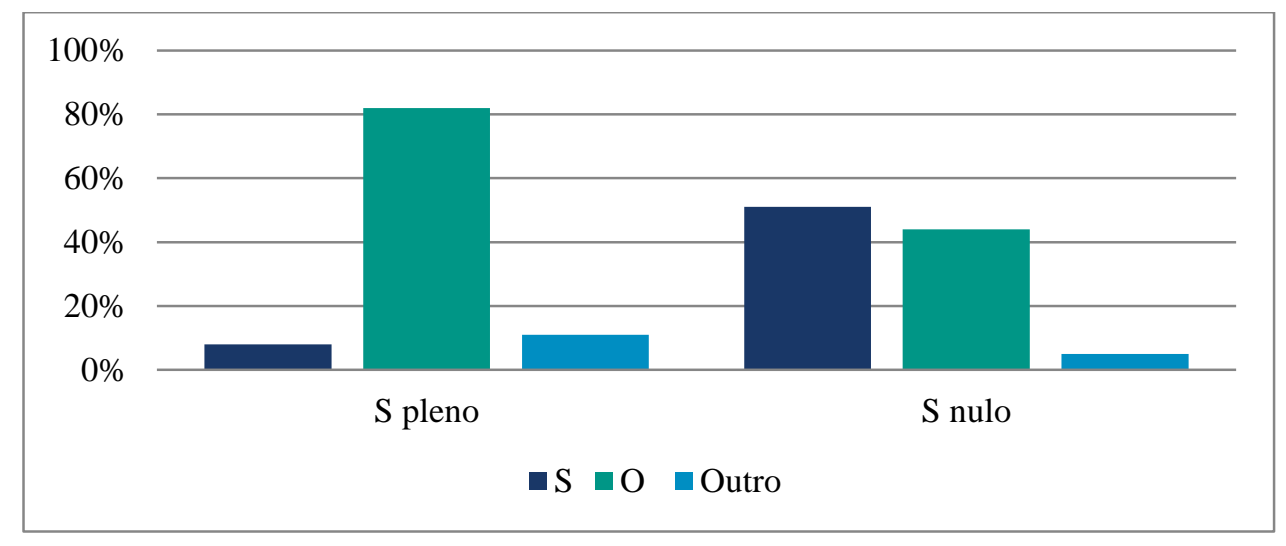

Figura 1: Resolução anafórica de sujeitos nulos e plenos em italiano L1 (Sorace \& Filiaci 2006: 355-6)

Num estudo sobre resolução anafórica (e catafórica) em contextos pragmaticamente neutros em PE, Lobo, Madeira e Silva (2017) mostram que, à semelhança do que acontece em italiano, nas gramáticas nativas adultas se verifica uma preferência forte do sujeito pleno por antecedentes em posição de objeto (85\% vs. $82 \%$ no grupo de controlo de Sorace e Filiaci, 2006). Contudo, uma comparação entre os resultados deste estudo e os de Sorace e Filiaci (2006) descritos acima sugere que as duas línguas diferem quanto à resolução de sujeitos nulos, que, em PE, recuperam preferencialmente antecedentes em posição de sujeito (90\% vs. $51 \%$ em italiano).

As propriedades semânticas do antecedente podem também condicionar as preferências de resolução dos pronomes plenos. Uma destas propriedades é a animacidade (e.g. Cardinaletti \& Starke, 1999). Tem sido proposto que os pronomes fortes, como é o caso dos pronomes de sujeito em italiano e PE, tendem a recuperar antecedentes animados (Barbosa, Duarte \& Kato, 2005; Cardinaletti, 2019; Morgado, Luegi \& Lobo, 2018). Num dos poucos estudos experimentais sobre este assunto em PE, Morgado, Luegi e Lobo (2018) mostram que, enquanto o sujeito nulo em frases como as ilustradas em (7) retoma preferencialmente o sujeito da oração adverbial, o sujeito pronominal pleno das frases em (8) é sensível à animacidade do constituinte em posição de objeto, perdendo-se a preferência pelo antecedente objeto quando este é [- animado]. Neste caso, observa-se opcionalidade na escolha do antecedente ( $51 \%$ objeto e $49 \%$ sujeito).

(7) a. Depois de o instrutor pintar o recruta no exercício militar, pro ficou camuflado no meio da vegetação.

b. Depois de o instrutor pintar o capacete no exercício militar, pro ficou camuflado no meio da vegetação.

(exemplos retirados de Morgado, Luegi \& Lobo, 2018: 200)

(8) a. Depois de o instrutor pintar o recruta no exercício militar, ele ficou camuflado no meio da vegetação.

b. Depois de o instrutor pintar o capacete no exercício militar, ele ficou camuflado no meio da vegetação. 
Apesar destes resultados, o papel que a animacidade desempenha na interpretação de pronomes está ainda pouco compreendido, já que a maioria dos estudos sobre resolução anafórica tem utilizado apenas antecedentes animados. Existe, pois, a necessidade de realizar mais investigação sobre o efeito da animacidade na resolução das diferentes formas pronominais. Outra lacuna que se pode identificar neste domínio prende-se com a escassez de estudos comparativos sobre as preferências interpretativas de sujeitos pronominais que incluam o PE.

\section{Questões de investigação}

Dado o atual estado da arte, formulámos as seguintes questões de investigação:

QI.1 Quando todos os antecedentes potenciais são animados, existem diferenças nas preferências de resolução de sujeitos pronominais plenos e nulos entre PE e italiano?

QI.2 Quando o antecedente em posição de sujeito é animado e o objeto é não animado, há diferenças nas preferências de resolução de sujeitos pronominais plenos e nulos entre PE e italiano?

Tendo em conta os resultados dos estudos prévios sobre resolução de sujeitos pronominais em PE e italiano em contextos pragmaticamente neutros (ver secção 2), fazemos as seguintes predições em relação à primeira questão de investigação:

P.1.a Quando todos os antecedentes forem animados, os sujeitos pronominais plenos retomarão preferencialmente um antecedente na posição de objeto em PE e italiano.

P.1.b Quando todos os antecedentes forem animados, os sujeitos nulos retomarão preferencialmente um antecedente na posição de sujeito em PE, mas não em italiano.

À luz dos resultados dos poucos trabalhos existentes sobre efeitos de animacidade na resolução de sujeitos pronominais (ver secção 2), fazemos as seguintes predições em relação à segunda questão de investigação:

P.2.a Quando o antecedente em posição de objeto for não animado e o sujeito animado, os sujeitos plenos retomarão preferencialmente antecedentes sujeito em italiano, mas, em PE, haverá opcionalidade entre os antecedentes sujeito e objeto.

P.2.b Quando o antecedente em posição de objeto for não animado e o sujeito animado, os sujeitos nulos retomarão preferencialmente um antecedente na posição de sujeito em PE, mas não em italiano, exibindo um comportamento semelhante ao encontrado quando todos os antecedentes potenciais são animados.

\section{Metodologia}

\subsection{Participantes}

Participaram neste estudo 15 falantes nativos de PE e 15 falantes nativos de italiano. Os falantes de PE eram estudantes universitários, com uma média de idade de 25.2 anos. Todos eram filhos de falantes monolingues de PE e residiram durante toda a sua vida em Portugal. O PE era a sua única língua materna. Os falantes de italiano eram também estudantes universitários, com uma média de idade de 26.9 anos. Todos eram 
filhos de falantes monolingues de italiano e tinham apenas o italiano como língua materna. Nenhum residiu fora de Itália por um período superior a 10 meses.

\subsection{Desenho experimental}

Com cada grupo foram utilizadas duas tarefas de escolha múltipla (com e sem pressão de tempo) para elicitar a interpretação preferencial em frases complexas em que a oração matriz é seguida de uma oração subordinada adverbial introduzida por quando. As tarefas foram administradas por ordem aleatória em duas ocasiões diferentes, separadas por um intervalo de uma semana. As tarefas tinham um desenho 2 x 2 , cruzando as seguintes variáveis: animacidade do objeto da oração matriz (animado vs. não animado) e tipo de sujeito pronominal da oração subordinada (pleno vs. nulo). Todas as tarefas incluíam 6 itens por condição, num total de 24 itens experimentais, e 24 distratores. Os itens e os distratores eram os mesmos nas tarefas usadas com os dois grupos, variando apenas a língua. Em todos os itens experimentais, os verbos da oração matriz eram transitivos e os da subordinada inacusativos. Todos estavam no passado (pretérito perfeito do indicativo em PE e passato prossimo do indicativo em italiano). A tabela 1 apresenta itens de exemplo.

\begin{tabular}{lll}
$\begin{array}{l}\text { Animacidade } \\
\text { do objeto }\end{array}$ & \multicolumn{1}{c}{ Pleno } & \multicolumn{1}{c}{ Tipo de sujeito pronominal } \\
\hline & $\begin{array}{l}\text { O porteiro viu o professor quando ele caiu } \\
\text { das escadas. }\end{array}$ & $\begin{array}{l}\text { O porteiro viu o professor quando [-] caiu } \\
\text { das escadas. }\end{array}$ \\
[+animado] & $\begin{array}{l}\text { Il portiere ha visto l'insegnante quando lui è è } \\
\text { caduto dalle scale. }\end{array}$ & $\begin{array}{l}\text { Il portiere ha visto l'insegnante quando [-] } \\
\text { è caduto dalle scale. }\end{array}$ \\
& $\begin{array}{l}\text { O menino viu o brinquedo quando ele caiu } \\
\text { da cadeira. }\end{array}$ & $\begin{array}{l}\text { O menino viu o brinquedo quando [-] caiu } \\
\text { da cadeira. }\end{array}$ \\
& $\begin{array}{l}\text { Il bambino ha visto il giocattolo quando lui } \\
\text { è caduto dalla sedia. }\end{array}$ & $\begin{array}{l}\text { Il bambino ha visto il giocattolo quando [-] } \\
\text { è caduto dalla sedia. }\end{array}$ \\
\hline
\end{tabular}

Tabela 1: Itens de exemplo

Na tarefa de escolha múltipla sem pressão de tempo, o participante lia uma frase e, com base na sua interpretação preferencial dessa frase, selecionava a opção mais adequada para completar uma afirmação como a apresentada no exemplo (9). As opções eram as seguintes: o sujeito da matriz, o objeto da matriz, e nem um nem outro. A sua ordem de apresentação era aleatória.

\section{(9) Exemplo de item de teste para a condição sujeito pleno + objeto animado}

O porteiro viu o professor quando ele caiu das escadas. caiu das escadas.

Opções: o porteiro; o professor; nem o porteiro nem o professor 
Na tarefa de escolha múltipla com pressão de tempo, adaptámos o procedimento habitualmente usado em tarefas de juízos de aceitabilidade rápidos (e.g., Bader \& Häussler, 2010; Hopp, 2007) para recolhermos dados de interpretação. Tal como acontece em tarefas de juízos de aceitabilidade rápidos, em cada item da tarefa de escolha múltipla, primeiro, aparecia um ponto de fixação durante $1500 \mathrm{~ms}$ e, em seguida, a frase era apresentada

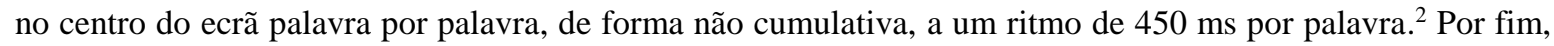
apareciam a frase a completar e as três opções, devendo o participante responder o mais rapidamente possível. Para cada item, foram gravados o tempo de resposta e a resposta do participante.

Esta tarefa foi usada por dois motivos. Primeiro, a apresentação rápida dos estímulos e a rapidez solicitada na resposta não dão tempo suficiente para os participantes pensarem sobre as suas respostas e forçam-nos a recorrer essencialmente ao seu conhecimento implícito. Assim, à semelhança das tarefas de juízos de aceitabilidade rápidos (e.g., Bader \& Haüssler, 2010; Bowles, 2011; Ellis, 2005; Godfroid et al., 2015), a tarefa de escolha múltipla com pressão de tempo que usámos permite recolher respostas inconscientes e automáticas aos estímulos linguísticos, o que não é garantido que aconteça numa tarefa em que o participante tenha tempo para pensar sobre as suas respostas e usar conhecimento explícito. Segundo, tem sido mostrado que tarefas offline com pressão de tempo, como tarefas de juízos de aceitabilidade rápidos, conseguem captar informação sobre processamento, uma vez que o ritmo da tarefa força o parser a seguir o seu percurso de processamento preferencial e não dá tempo suficiente para uma reanálise completa da frase (para uma síntese, ver Hopp, 2007). Nestas tarefas, o tempo de resposta é interpretado como um indicador do esforço de processamento (tempos mais longos refletem mais esforço). A tarefa de escolha múltipla com pressão de tempo complementa, assim, a tarefa sem pressão de tempo, permitindo-nos obter um retrato mais completo da resolução de sujeitos pronominais em PE e italiano.

\subsection{Análise dos dados}

A análise estatística foi realizada com modelos de efeitos mistos, em que foram computados como efeitos fixos as variáveis tipo de sujeito e tipo de objeto e como efeitos aleatórios as variáveis participantes e itens. Os efeitos fixos foram codificados contrastivamente com os códigos 0.5 e - 0.5 para comparar dois níveis do mesmo efeito fixo (e.g., objeto animado $=0.5 v s$. objeto não animado $=-0.5$ ). Seguindo Cunnings (2012) e Linck \& Cunnings (2015), as análises incluíram interceções aleatórias para participantes e itens e declives aleatórios por participante para as variáveis tipo de sujeito e tipo de objeto e a sua interação. A análise estatística foi realizada em R, usando o pacote lme4. Mais especificamente, foi usada a função lmer (modelo misto linear) para a análise dos tempos de resposta da tarefa com pressão de tempo e a função glmer (modelo misto linear generalizado), com a especificação "family=binomial”, para a análise das respostas nas tarefas com e sem pressão de tempo. Como a taxa de seleção da opção "nem antecedente sujeito nem antecedente objeto" foi muito baixa, variando entre $0 \%$ e $7 \%$, as respostas foram tratadas como binárias e codificadas como 'antecedente sujeito' = 1 e 'antecedente não sujeito' $=0$. Nos casos em que era pertinente determinar se a diferença entre a escolha de antecedentes sujeito e não sujeito era significativa numa dada condição experimental (e.g., sujeito nulo + objeto animado), foram realizadas análises adicionais com um modelo misto linear generalizado, em que foram computados como efeito fixo a variável antecedente (sujeito vs. não sujeito) e como efeitos aleatórios as variáveis participantes e itens.

\footnotetext{
${ }^{2} 400$ - 450 ms é o ritmo tipicamente usado neste tipo de tarefas, uma vez que se assume que é uma janela de tempo suficiente para os falantes completarem todos os processos de compreensão normais (cf. Bader \& Häussler, 2010; Hopp, 2007).
} 


\section{Resultados}

Na tarefa de escolha múltipla sem pressão de tempo, os falantes de PE e de italiano têm preferências diferentes na resolução de sujeitos pronominais. A análise estatística das respostas dos falantes de PE revela um efeito principal de tipo de sujeito pronominal (estimativa $=-7.2673, \mathrm{EP}=1.5180, p<.001$ ), mas nenhum efeito de animacidade do objeto (estimativa $=.3444, \mathrm{EP}=1.1533, p=.299$ ), nem nenhuma interação entre este fator e o tipo de sujeito (estimativa $=-1.4026, \mathrm{EP}=2.6692, p=-.525$ ). Como a Figura 2 mostra, em PE, os sujeitos pronominais plenos retomam antecedentes em posição de objeto e os nulos retomam antecedentes em posição de sujeito, independentemente da animacidade do objeto. Ao contrário do que acontece em PE, em italiano, há um efeito principal de animacidade do objeto (estimativa $=1.9746, \mathrm{EP}=.6244, p=.00157$ ), um efeito de tipo de sujeito próximo do limiar de significância estatística (estimativa $=1.2956, \mathrm{EP}=.7394, p=.07980$ ) e uma interação muito significativa entre as variáveis tipo de sujeito e animacidade do objeto (estimativa $=4.6515, \mathrm{EP}$ $=1.1628, p<.001$ ). Como se pode observar na Figura 2, em italiano, a interpretação do sujeito pronominal pleno varia de acordo com a animacidade do objeto. Quando o objeto é animado, o sujeito pleno retoma preferencialmente o antecedente na posição de objeto. Já quando o objeto não é animado, o sujeito pleno do italiano tende a recuperar o antecedente na posição de sujeito, contrariamente ao que acontece em PE. Também no caso dos sujeitos nulos as preferências de interpretação são diferentes em italiano e em PE. Quando o objeto é animado, no grupo italiano, não há uma diferença significativa entre a escolha de antecedentes sujeito e objeto (estimativa $=.41467, \mathrm{EP}=.65165, p=.525$ ). Só se observa uma preferência na resolução de sujeitos nulos quando o objeto não é animado. Neste caso, tendem a retomar o antecedente na posição de objeto (diferença entre objeto e sujeito: estimativa $=.92083, \mathrm{EP}=.31685, p=.00366$ ). Estes resultados sugerem que o sujeito nulo retoma preferencialmente antecedentes não animados em italiano.

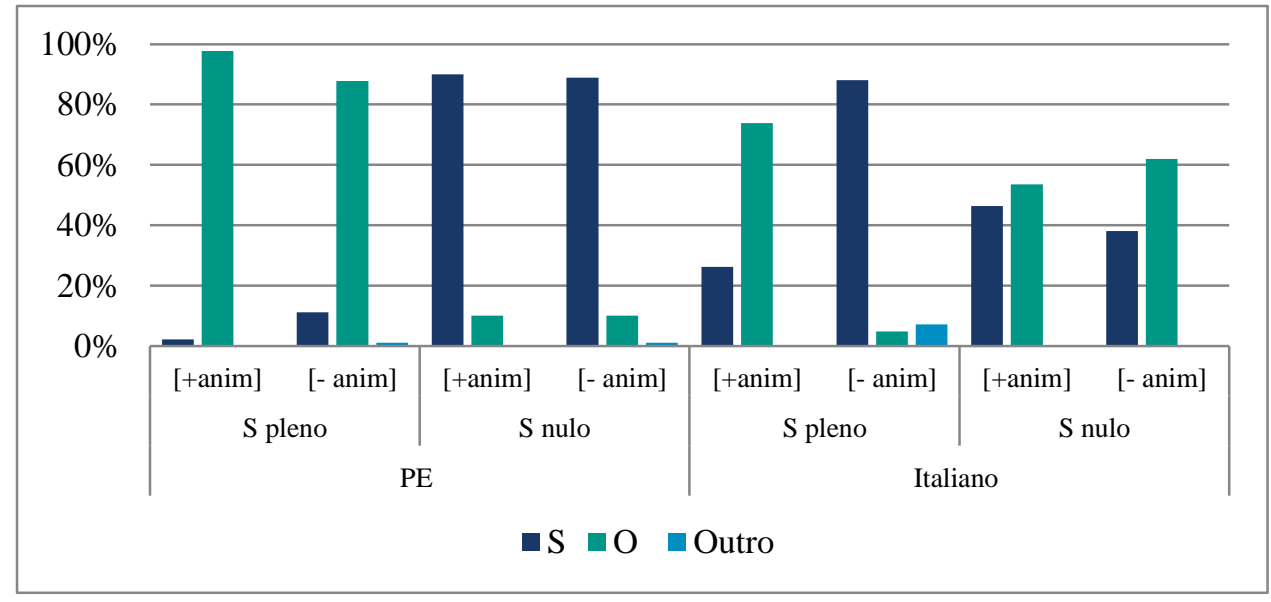

Figura 2: Interpretação de sujeitos pronominais em PE e italiano na tarefa sem pressão de tempo por tipo de sujeito e tipo de objeto

Os resultados da tarefa de escolha múltipla com pressão de tempo são praticamente iguais aos obtidos na tarefa anterior. À semelhança do que acontece nessa tarefa, na tarefa com pressão de tempo, há apenas um efeito principal de tipo de sujeito pronominal em PE (estimativa $=-5.53164, \mathrm{EP}=1.09437, p<.001$ ). Nenhum outro 
efeito ou interação é significativo ( $p s \geq .462)$. Em italiano, encontramos um efeito principal de animacidade do objeto (estimativa $=1.3222$, $\mathrm{EP}=.6434, p=.00153$ ), um efeito de tipo de sujeito pronominal próximo de significância estatística (estimativa $=1.2956, \mathrm{EP}=.7559, p=.08024$ ) e uma interação muito significativa entre este fator e a animacidade do objeto (estimativa $=4.7671, \mathrm{EP}=1.1378, p<.001$ ), tal como acontece na tarefa sem pressão de tempo. A única diferença nos resultados das duas tarefas usadas no estudo está na interpretação do sujeito nulo em italiano. Contrariamente ao que acontece na tarefa sem pressão de tempo, na tarefa de escolha múltipla com pressão de tempo, os falantes de italiano exibem opcionalidade na resolução de sujeitos nulos não apenas quando o objeto é animado (antecedente sujeito vs. não sujeito: estimativa $=.14373 ; \mathrm{EP}=.31905 ; p=$ .652 ), mas também quando não é (antecedente sujeito vs. não sujeito: estimativa $=.3662 ; \mathrm{EP}=.5566 ; p=.511$ ), como se pode ver na Figura 3.

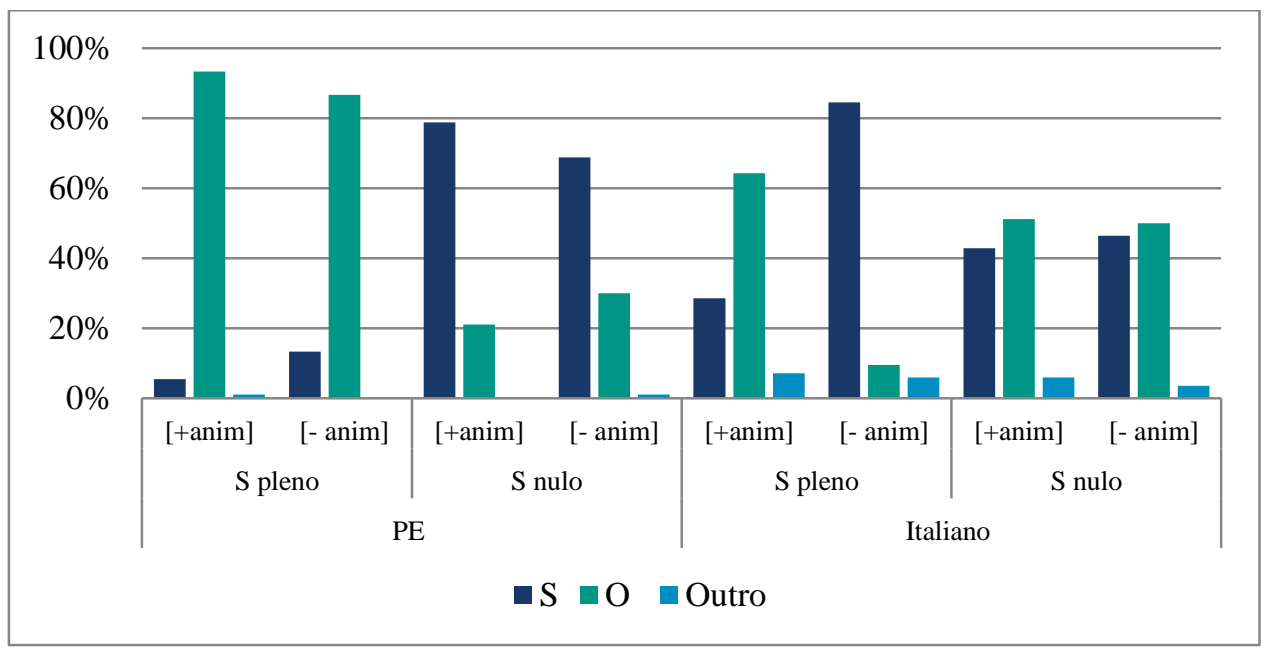

Figura 3: Interpretação de sujeitos pronominais em PE e italiano na tarefa com pressão de tempo por tipo de sujeito e tipo de objeto

Consideremos, por fim, os tempos de resposta na tarefa de escolha múltipla com pressão de tempo. Como mostra a tabela 2, em PE, os tempos de resposta são significativamente mais longos na condição sujeito pleno + objeto não animado do que na condição sujeito pleno + objeto animado, o que é o único indício neste estudo de efeitos de animacidade na resolução de sujeitos pronominais em PE. Em italiano, só há diferenças significativas nos tempos de resposta relacionadas com a animacidade do objeto quando o sujeito é nulo. Neste caso, os tempos são mais longos na condição com objeto animado, ou seja, quando todos os antecedentes potenciais são animados. Este resultado constitui um indício de que o sujeito nulo em italiano prefere antecedentes não animados, havendo maior esforço de processamento quando esta preferência não é respeitada. 
Tabela 2: Tempos de resposta na tarefa com pressão de tempo

\begin{tabular}{|c|c|c|c|c|c|}
\hline & \multicolumn{2}{|r|}{$\mathbf{P E}$} & \multicolumn{2}{|r|}{ Italiano } \\
\hline & & $\begin{array}{c}\text { Média } \\
(\mathrm{ms})\end{array}$ & $\begin{array}{c}\text { Comparação } \\
\text { [+anim] vs. [-anim] }\end{array}$ & $\begin{array}{c}\text { Média } \\
(\mathrm{ms})\end{array}$ & $\begin{array}{c}\text { Comparação } \\
\text { [+anim] vs. [-anim] }\end{array}$ \\
\hline \multirow{3}{*}{$\begin{array}{c}S \\
\text { pleno }\end{array}$} & [+animado] & 5575 & estimativa $=2241.0, E P=$ & 6465 & estimativa $=-908.4, E P=$ \\
\hline & & & $1398.6, t=2.002$ & 5557 & 953.0, \\
\hline & [-animado] & 7766 & $p=.04680321 *$ & & $t=-.953, p=.3419674$ \\
\hline \multirow{2}{*}{$\begin{array}{c}S \\
\text { nulo }\end{array}$} & [+animado] & 6565 & estimativa $=-22.2, \mathrm{EP}=$ & 6923 & estimativa $=-1655.3, E P=$ \\
\hline & [-animado] & 6543 & $\begin{array}{c}932.4 \\
t=-.024, p=.9808795\end{array}$ & 5268 & $\begin{array}{c}824.2 \\
t=-2.008, p=.04625534 *\end{array}$ \\
\hline
\end{tabular}

\section{Discussão e conclusões}

Retomamos as questões de investigação enunciadas em 3., a que responderemos tendo em conta os resultados apresentados na secção anterior.

QI.1: Quando todos os antecedentes potenciais são animados, existem diferenças nas preferências de resolução de sujeitos pronominais nulos e plenos entre PE e italiano?

Da análise dos dados, pode concluir-se que, no caso dos sujeitos plenos em ambas as tarefas, as duas línguas apresentam preferências idênticas de resolução anafórica, uma vez que o sujeito pleno retoma preferencialmente o objeto, o que confirma a nossa predição (P.1.a) de que não há diferenças entre PE e italiano.

Porém, no que toca à interpretação dos sujeitos nulos, as preferências são diferentes em italiano e em PE, em ambas as tarefas, confirmando a P.1.b, visto que, em PE, o sujeito nulo retoma o sujeito, e, em italiano, não há uma preferência clara pela retoma do sujeito ou do objeto. Este resultado está em linha com os de Sorace \& Filiaci (2006).

QI.2: Quando o antecedente em posição de sujeito é animado e o objeto é não animado, há diferenças nas preferências de resolução de sujeitos pronominais nulos e plenos entre PE e italiano?

De acordo com os nossos resultados, as preferências de interpretação dos sujeitos nulos são diferentes em italiano e em PE em ambas as tarefas. Em PE, o sujeito nulo retoma o sujeito, enquanto, em italiano, há uma preferência pela retoma do objeto na tarefa sem pressão de tempo, não se observando preferências na tarefa com pressão de tempo. Estes resultados confirmam a nossa predição 2.b (os sujeitos nulos retomarão preferencialmente um antecedente na posição de sujeito em PE, mas não em italiano, exibindo um comportamento semelhante ao encontrado quando todos os antecedentes potenciais são animados) no que diz respeito ao PE mas não ao italiano. A preferência do grupo italiano pelo antecedente objeto na tarefa sem pressão de tempo, em conjunto com o maior tempo de resposta na condição [+animado] do que na condição [-animado] na tarefa com pressão de tempo, constituem evidência de que, em italiano, o sujeito nulo prefere antecedentes [-animados]. Note-se que, na tarefa com pressão de tempo, maior tempo de resposta é um indício de esforço de processamento.

Relativamente às preferências de interpretação dos sujeitos plenos, as diferenças entre as duas línguas observam-se em todas as tarefas. Em PE, o sujeito pleno retoma sempre antecedentes em posição de objeto, enquanto, em italiano, se verifica um efeito de animacidade, que se revela pela preferência por antecedentes em 
posição de sujeito apenas quando o objeto não é animado. Estes resultados confirmam a nossa predição 2.a (os sujeitos plenos retomarão preferencialmente antecedentes sujeito em italiano, quando o objeto é não animado, mas, em PE, haverá opcionalidade entre os antecedentes sujeito e objeto) no que se refere ao italiano, mas não ao PE. No entanto, embora os falantes de PE mantenham a preferência pelo objeto quando este não é animado, observa-se um efeito de animacidade nos tempos de resposta na tarefa com pressão de tempo, que são significativamente maiores na condição de objeto [-animado] do que na de [+animado]. Esta diferença aponta para um conflito entre a tendência para o pronome pleno retomar um antecedente não sujeito e uma possível tendência para retomar antecedentes animados, que é resolvido em PE pela manutenção da preferência por um antecedente numa posição estruturalmente menos proeminente, seguindo a Estratégia da Posição do Antecedente.

Os efeitos de animacidade que se observam em PE são, assim, mais fracos do que havia sido proposto em trabalhos anteriores (e.g. Morgado, Luegi \& Lobo, 2018). Uma possível explicação para esta diferença pode ser a ordem das orações nos itens experimentais. O estudo de Morgado et al (2018) tem a ordem subordinada matriz, enquanto, no presente estudo, a ordem é matriz - subordinada. Como tem sido mostrado em trabalhos sobre o espanhol (cf. Chamorro, 2018), a ordem das orações pode influenciar a resolução de sujeitos pronominais.

Em resumo, nos contextos investigados no presente estudo, em PE, a posição do antecedente é um fator mais relevante na resolução de sujeitos pronominais do que a animacidade. Pelo contrário, em italiano, é a animacidade o fator mais preponderante, o que se traduziu, como mostraram os nossos resultados, na preferência pela retoma de antecedentes animados com sujeitos plenos, e de antecedentes não animados com sujeitos nulos. Assim, estes resultados confirmam a existência de microvariação na resolução anafórica em PE e em italiano.

É possível, pois, que estas diferenças entre as duas línguas na resolução dos sujeitos pronominais estejam relacionadas com diferenças na arquitetura dos sistemas pronominais entre o italiano e o PE, em linha com a proposta de Filiaci, Sorace e Carreiras (2014) para os pronomes sujeito do espanhol e do italiano. O italiano tem um sistema tripartido de pronomes sujeito (fortes, fracos e nulos), pelo que se espera uma maior especialização dos pronomes, associando-se o pronome forte à propriedade [+animado] e o pronome nulo à propriedade [-animado] (Cardinaletti \& Starke, 1999).

Já no PE esta especialização não se observa, uma vez que é uma língua que possui um sistema bipartido de pronomes sujeito (fortes e nulos), sendo ambos os pronomes, pleno e nulo, subespecificados para animacidade. Esta subespecificação terá como consequência uma maior permeabilidade a efeitos discursivos. O efeito da posição do antecedente é, particularmente, visível nesta língua, traduzindo-se, para o pronome nulo, na escolha do antecedente na posição de sujeito, numa estratégia de manutenção de tópico, enquanto a escolha do antecedente na posição de objeto pelo pronome pleno reflete a mudança de tópico discursivo (e.g. Carminati, 2002). Por seu turno, em italiano, por os pronomes serem mais especializados, são menos permeáveis a efeitos discursivos, o que se reflete no maior peso atribuído ao fator animacidade na escolha do potencial antecedente para o pronome anafórico.

Este tópico carece de aprofundamento. Seria importante alargar este estudo a outras línguas românicas de sujeito nulo, em particular o espanhol, que, tal como o PE, tem um sistema pronominal bipartido. Exploraremos estas questões em trabalho futuro.

Os resultados obtidos mostram que, ao contrário do que tem sido defendido na literatura (cf. Filiaci, 2010; Filiaci, Sorace \& Carreiras, 2014), a microvariação existe não só na resolução de sujeitos pronominais plenos como também na resolução de sujeitos pronominais nulos. 


\section{Referências}

Alonso-Ovalle, Luis, Susana Fernández-Solera, Lyn Frazier \& Charles Clifton (2002) Null vs. overt pronouns and the topic-focus articulation in Spanish. Journal of Italian Linguistics 14, pp. 151-169.

Bader, Markus \& Jana Häussler (2010) Toward a model of grammaticality judgments. Journal of Linguistics, 46 (2), pp. 273-330.

Barbosa, Pilar, Maria Eugênia Duarte \& Mary Kato (2005) Null subjects in European and Brazilian Portuguese. Journal of Portuguese Linguistics 4 (2), pp. 11-52.

Bowles, Melissa (2011) Measuring implicit and explicit linguistic knowledge: What can heritage language learners contribute? Studies in Second Language Acquisition 33 (2), pp. 247-271.

Cardinaletti, Anna (2019) Cliticization as extraction: The Big DP Hypothesis revisited. Revista da Associação Portuguesa de Linguística 5, pp. 1-16.

Cardinaletti, Anna, \& Michal Starke (1999) The typology of structural deficiency: A case study of the three classes of pronouns. In Henk van Riemsdijk (Ed.) Clitics in the languages of Europe. Berlin/New York: Mouton de Gruyter, pp. 145-233.

Carminati, Maria Nella (2002) The processing of Italian subject pronouns. Dissertação de doutoramento, University of Massachusetts.

Chamorro, Gloria (2018) Offline interpretation of subject pronouns by native speakers of Spanish. Glossa: A Journal of General Linguistics 3 (1), p. 27.

Costa, João \& Joana Ambulate (2010) The acquisition of embedded subject pronouns in European Portuguese. In. Michael Iverson, Ivan Ivanov, Tiffany Judy, Jason Rothman, Roumyana Slabakova \& Marta Tryzna (Eds.) Proceedings of the 2009 Mind/Context Divide Workshop. Somerville, MA: Cascadilla Proceedings Project, pp. 1-12.

Cunnings, Ian (2012) An overview of mixed-effects statistical models for second language researchers. Second Language Research 28 (3), pp. 369-382.

Ellis, Rod (2005) Measuring implicit and explicit knowledge of a second language: A psychometric study. Studies in Second Language Acquisition 27 (2), pp. 141-172.

Filiaci, Francesca (2010) Null and overt subject biases in Spanish and Italian: A cross-linguistic comparison. In. Claudia Borgonovo, Manuel Español-Echevarría \& Philippe Prévost (Eds.) Selected Proceedings of the 12th Hispanic Linguistics Symposium. Somerville, MA: Cascadilla Proceedings Project, pp. 171-182.

Filiaci, Francesca, Antonella Sorace \& Manuel Carreiras (2014) Anaphoric biases of null and overt subjects in Italian and Spanish: a cross-linguistic comparison. Language, Cognition and Neuroscience 29 (7), pp. 825843.

Godfroid, Aline, Shawn Loewen, Sehoon Jung, Ji-Hyun Park, Susan Gass \& Rod Ellis (2015) Timed and untimed grammaticality judgements measure distinct types of knowledge. Studies in Second Language Acquisition 37 (2), pp. 269-297.

Hopp, Holger (2007) Ultimate attainment at the interfaces in second language acquisition: Grammar and processing. Dissertação de doutoramento, University of Groningen.

Linck, Jared \& Ian Cunnings (2015) The utility and application of mixed-effects models in second language research. Language Learning 65, pp. 185-207. 
Lobo, Maria (2013) Sujeito nulo: Sintaxe e interpretação. In. Eduardo Buzaglo Paiva Raposo, Maria Fernanda Bacelar do Nascimento, Maria Antónia Coelho da Mota, Luísa Segura \& Amália Mendes (Eds.) Gramática do Português. Lisboa: Fundação Calouste Gulbenkian, pp. 2309-2335.

Lobo, Maria (2016) Sujeitos nulos: gramática do adulto, aquisição de L1 e variação dialetal. In. Ana Maria Martins \& Ernestina Carrilho (Eds.) Manual de Linguística Portuguesa. Berlin: De Gruyter, pp. 558-580.

Lobo, Maria, Ana Madeira \& Carolina Silva (2020) Interpretação de pronomes sujeito anafóricos e catafóricos por falantes de português L2: efeitos da língua materna. Revista da Associação Portuguesa de Linguística 3, pp. 135-153.

Luegi, Paula (2012) Processamento de sujeitos pronominais em Português: efeito da posição estrutural do antecedente. Dissertação de doutoramento, Faculdade de Letras da Universidade de Lisboa.

Montalbetti, Mario (1984) After binding. On the interpretation of pronouns. Dissertação de doutoramento, MIT.

Morgado, Sara, Paula Luegi \& Maria Lobo (2018) Efeitos de animacidade do antecedente na resolução de pronomes sujeito. Revista da Associação Portuguesa de Linguística 4, pp. 190-205.

Sorace, Antonella, \& Francesca Filiaci (2006) Anaphora resolution in near-native speakers of Italian. Second Language Research 22 (3), pp. 339-368. 